\title{
Quantitative Correlation of High Quality a-Si:H p-i-n Solar Cell Characteristics with Properties of the Bulk and p/i Interface Region
}

\author{
J. M. Pearce, R. J. Koval, R.W. Collins, and C.R. Wronski \\ Center for Thin Film Devices, The Pennsylvania State University, University Park, PA 16802
}

\begin{abstract}
Studies have been carried out on high quality hydrogenated amorphous silicon (a-Si:H) p-i-n solar cells with protocrystalline i-layers to establish the nature of $\mathrm{p} / \mathrm{i}$ interfaces and to quantify their contributions to various solar cell characteristics. The $\mathrm{p}-\mathrm{a}-\mathrm{SiC}: \mathrm{H}: \mathrm{B} / \mathrm{i}-\mathrm{a}-\mathrm{Si} \mathrm{H} / \mathrm{n}-\mu \mathrm{c}-$ $\mathrm{Si}: \mathrm{H}: \mathrm{P}$ cell structures used had the a-Si:H i-layers deposited from hydrogen diluted silane with $\mathrm{R} \equiv\left[\mathrm{H}_{2}\right] /\left[\mathrm{SiH}_{4}\right]=10$. The high quality $\mathrm{p} / \mathrm{i}$ interface regions obtained with $R=10$, indicated by the high and stable open circuit voltage $\left(V_{o c}\right)$ values, were further improved by increasing $\mathrm{R}$ in the $200 \AA$ of a-Si:H adjacent to the a-SiC:H layer. From the systematic improvement and ability to obtain $\mathrm{p} / \mathrm{i}$ interface regions with outstanding quality, it was possible to track their contributions to cell characteristics relative to those from the bulk. Results of dark current voltage $\left(J_{D}-V\right)$ and short circuit current-open circuit voltage $\left(\mathrm{J}_{\mathrm{sc}}-\mathrm{V}_{\mathrm{oc}}\right)$ characteristics are presented which clearly demonstrate that even high quality interface regions in $\mathrm{p}$-i$\mathrm{n}$ cells can mask some contributions of protocrystalline bulk layers. Results are also presented and discussed on how the relative contributions of bulk and p/i interfaces can be isolated and quantified so they can be used as inputs for reliable analysis of solar cell characteristics.
\end{abstract}

\section{INTRODUCTION}

Open circuit voltage $\left(\mathrm{V}_{\mathrm{oc}}\right)$ is one of the central factors that determine the overall performance of amorphous silicon solar cells. There has been significant progress in increasing the open circuit voltages in both $p-i-n$ and $n-i-p$ a-Si:H solar cells, however, the physical phenomena that underlie their magnitude and stability are not fully understood. The open circuit voltage can also be limited by intrinsic layer recombination. Thus, there have been a large number of attempts to relate the properties of the intrinsic materials in a-Si:H $p$-i-n and $n-i-p$ solar cells to the magnitude and stability of their $V_{o c}[1,2]$. Unfortunately, the success of these attempts have been incomplete due predominantly to the inability to quantify the individual contributions of the bulk i-layer and those from the $p / i$ interface region to the cell characteristics. This is partially due to the fact that in such studies both the $\mathrm{p} / \mathrm{i}$ interface regions and the bulk $\mathrm{i}$ layer were changed simultaneously. Such, absence of reliably quantified information about the individual contributions of the bulk and interface seriously limits the ability of systematically (rather than empirically) improving the $V_{\text {oc. }}$ In the work reported here the contributions of the same protocrystalline i-layers $[3,4]$ with different $p / i$ interface regions to the dark $\mathrm{J}-\mathrm{V}$ and $\mathrm{J}_{\mathrm{sc}}-\mathrm{V}_{\mathrm{oc}}$ characteristics were quantified. Because of the high quality of the intrinsic material, the effect of good p/i interface regions can be identified on both the $J_{D}-V$ and $V_{o c}$ characteristics. This allows the contributions to the $V_{o c}$ of different $p / i$ interface regions as well as that of the bulk to be quantified for cell structures that exhibit both high $\mathrm{V}_{\mathrm{oc}} \mathrm{S}$ and high Fill Factors (0.72 for $4000 \AA$ i layers).

Even though large improvements have been made in the quality of both the i-layers and the p/i interfaces, a better understanding of how they affect cell characteristics is still required before reliable analyses can be carried out of cell performance and stability. This study establishes and quantifies the contributions of $p / i$ interface regions to various cell characteristics in high quality $\mathrm{p}-\mathrm{i}-\mathrm{n}$ a-Si:H solar cells with protocrystalline ilayers.

\section{EXPERIMENTAL}

Baseline, state-of-the-art solar cells were fabricated with intrinsic protocrystalline $\mathrm{Si}: \mathrm{H}$ by RF plasma enhanced chemical vapor deposition (PECVD) with $\mathrm{SiH}_{4}$ diluted with hydrogen with a dilution ration $\mathrm{R} \equiv\left[\mathrm{H}_{2}\right] /\left[\mathrm{SiH}_{4}\right]=$ 10 under conditions previously described [4]. The cells were fabricated on specular $\mathrm{SnO}_{2}$ consisting of $250 \AA$ a-

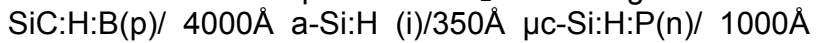
$\mathrm{Cr}$. The high quality of the protocrystalline i-layer, deposited at $200^{\circ} \mathrm{C}$ has been clearly established from detailed studies of cells with different thicknesses [5] and corresponding thin film materials [6]. In these $p$-i-n cells $200 \AA \mathrm{p} / \mathrm{i}$ interface regions were systematically changed by increasing their $\mathrm{R}$ from 10 to 40 [7]. To minimize possible contributions of shunts to the dark J-V's at low forward bias these cells had small areas $\left(0.02 \mathrm{~cm}^{2}\right)$ isolated by reactive ion etching of the $\mathrm{n} \mu \mathrm{c}-\mathrm{Si}: \mathrm{H}$ layers. The $\mathrm{J}_{\mathrm{D}}-\mathrm{V}$ and $\mathrm{J}_{\mathrm{sc}}-\mathrm{V}_{\mathrm{oc}}$ characteristics were measured at $25^{\circ} \mathrm{C}$ with the latter being obtained with illuminations between $\sim 10^{-7}$ and 1 sun from an Oriel solar simulator. Results were obtained on cells from the annealed state (4 hours at $170^{\circ} \mathrm{C}$ ) to the 1 sun degraded steady state (DSS) obtained after 100 hours of illumination [8].

\section{RESULTS}

The $\mathrm{p} / \mathrm{i}$ interfaces in the baseline structures were of high quality, as reflected by the high values of fill factor (FF) and $V_{o c}$ and the liner dependence of $J_{s c}$ on intensity over the entire range of illumination. However, it was found that the $V_{o c}$ could be further improved by

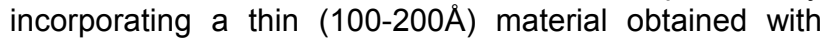
higher $\mathrm{H}_{2}$ dilutions in the interface between the $\mathrm{p}$ and $\mathrm{i}$ regions [9]. Systematic improvements were obtained in the $\mathrm{p} / \mathrm{i}$ interface regions, which resulted in even higher stabilized $V_{\text {oc }}$ 's for higher diluted interfaces. For a $200 \AA$ thick interface $R=40$ material resulted in the highest $V_{o c}$ as seen in Table 1. If the dilution in the interface layer is 
increased further the material undergoes the amorphous to microcrystalline phase transition [3] and the $\mathrm{V}_{\mathrm{oc}}$ of the cell declines. From the systematic improvements in the interface regions it was possible to track their contributions to cell characteristics relative to those from the bulk.

\begin{tabular}{|c|c|c|c|}
\hline $\begin{array}{l}\text { p/i interface } \\
\mathrm{R}=\left[\mathrm{H}_{2}\right] /\left[\mathrm{SiH}_{4}\right]\end{array}$ & $\begin{array}{l}\text { 1 sun } V_{\text {oc }} \\
\text { Anneale } \\
\text { d State } \\
\text { (V) }\end{array}$ & $\begin{array}{c}1 \text { sun } V_{o c} \\
\text { Degraded } \\
\text { Steady State } \\
\text { (V) }\end{array}$ & $\begin{array}{c}\Delta \mathbf{V}_{\text {oc }} \\
\text { (V) }\end{array}$ \\
\hline 0 & 0.822 & 0.808 & -0.014 \\
\hline 10 & 0.872 & 0.866 & -0.006 \\
\hline 15 & 0.870 & 0.880 & +0.010 \\
\hline 20 & 0.905 & 0.894 & -0.011 \\
\hline 40 & 0.933 & 0.918 & -0.015 \\
\hline
\end{tabular}

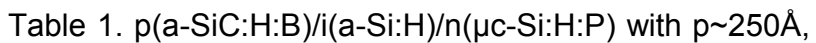
$\mathrm{i} \sim 4000 \AA, p / i \sim 200 \AA, n \sim 350 \AA$ all with identical $R=10 \mathrm{i}$ layers with different diluted $\mathrm{p} / \mathrm{i}$ interfaces.

It is well known that increases in $V_{o c}$ of $p$-i-n or $n-i-p$ solar cells can be obtained with bulk i layers having wider bandgaps. Unfortunately, the wider bandgap materials show less optical absorption of the solar spectrum and thus cause a reduction in the short circuit current density $\left(\mathrm{J}_{\mathrm{sc}}\right)$, so they are unsuitable for use in the bulk intrinsic layer of high efficiency single junction cells. The absence of limitations due to the built in potential for cells studied here where established with results of $V_{o c}$ at low temperatures and at intensities greater than one sun [7].

The effect of the improved interfaces on the annealed state dark J-V characteristic is illustrated in Figure 1, where results for the baseline and optimized ( $R=40 \mathrm{p} / \mathrm{i}$ interface) are shown for the annealed state. It can be seen in Figure 1, that introducing the optimized $\mathrm{p} / \mathrm{i}$

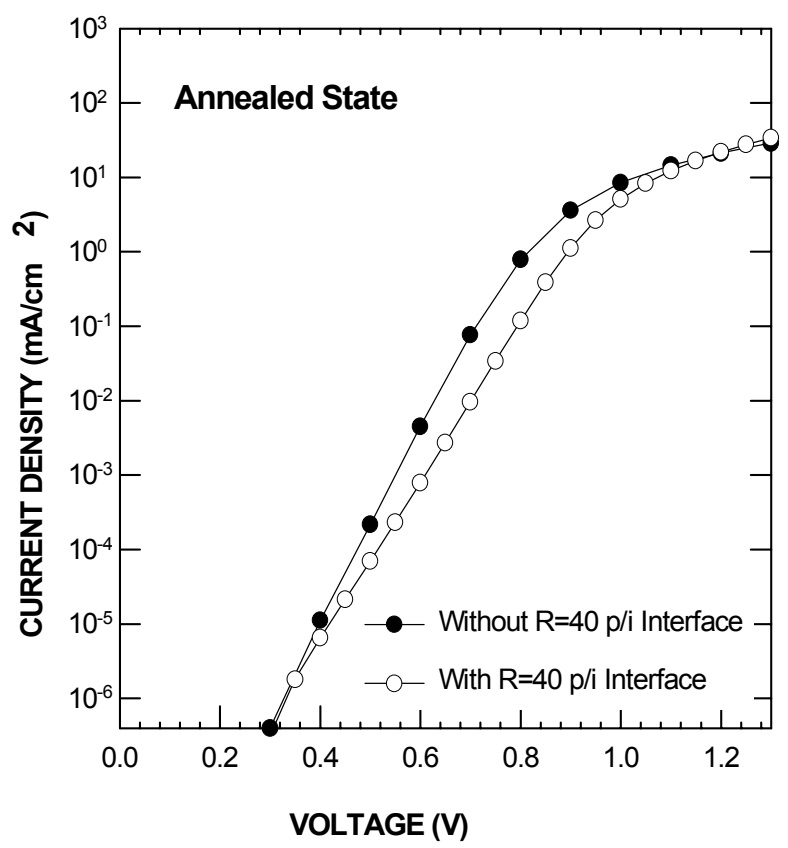

Fig. 1. The annealed state dark J-V characteristics of for an $R=10$ cell and $R=10$ cell with an $R=40$ p/i interface region. interface region has a profound effect on the dark J-V characteristics, where the exponential currents for voltages between $0.4 \mathrm{~V}$ and $1 \mathrm{~V}$ are reduced up to an order of magnitude.

Since these currents are associated with the generation and recombination of carriers this decrease can be attributed to a significant reduction of recombination in the $\mathrm{p} / \mathrm{i}$ interface region, which originally partially obscures the contributions of the bulk. It is important to note here that the extent to which $\mathrm{p} / \mathrm{i}$ interfaces can dominate the dark J-V characteristics has not been fully taken into account in the numerous modeling results of annealed $\mathrm{p}$-i-n characteristics. In such analysis arbitrary assumptions are made about the possible contributions of the $\mathrm{p} / \mathrm{i}$ interface relative to the bulk in order to ascertain their properties. Such importance of the $\mathrm{p} / \mathrm{i}$ interface in determining the dark $\mathrm{J}-\mathrm{V}$ characteristics is acutely evident in these high quality protocrystalline i-layers and cannot be ignored particularly in the annealed state. It is expected that as the quality of the bulk declines the contributions of the p/i interface to the dark $\mathrm{J}-\mathrm{V}$ characteristic will be reduced. This is indeed the case and is illustrated in Figure 2, where dark J-V characteristics for the cells in Figure 1 are shown in the degraded steady state (DSS) obtained with 1 sun illumination at $25^{\circ} \mathrm{C}$. Now, the dark J-V's are nearly identical since the generation- recombination currents are in this case dominated by the light induced defects in the bulk even for the baseline cell.

It is well known that $V_{o c}$, and in particular its stability, are very sensitive to the properties of the $p$ layers and the $\mathrm{p} / \mathrm{i}$ interface regions. Nevertheless, it still depends on the properties of the bulk intrinsic layers and in particular their bandgap. We find that it is possible to separate the

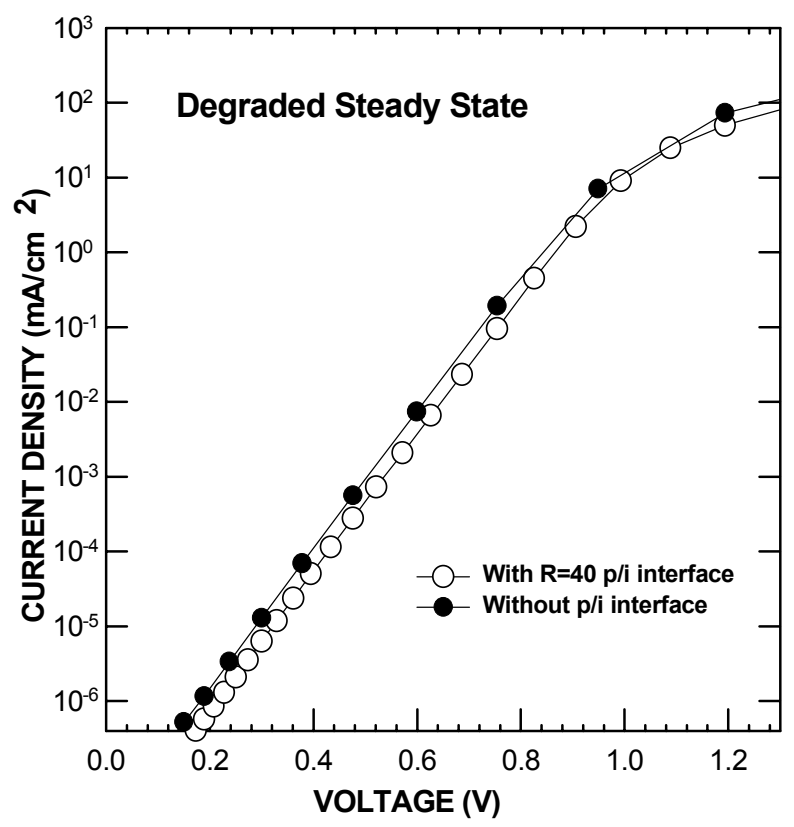

Fig. 2. The 1 sun degraded steady state dark J-V characteristics of an $R=10$ cell and an $R=10$ cell with an $\mathrm{R}=40 \mathrm{p} / \mathrm{i}$ interface region. 
contributions for the bulk and the $\mathrm{p} / \mathrm{i}$ interface region from $\mathrm{J}_{\mathrm{sc}}-\mathrm{V}_{\mathrm{oc}}$ characteristics obtained over a wide range of illumination intensities. This is illustrated in Figure 3, where the $\mathrm{J}_{\mathrm{sc}}-\mathrm{V}_{\mathrm{oc}}$ characteristics for the baseline and optimized cells in the annealed state are shown for illumination levels between 1 and $10^{-7}$ suns. The solid line is a guide to the eye indicating the intensities over which the $\mathrm{J}_{\mathrm{sc}}-\mathrm{V}_{\mathrm{oc}}$ characteristics for the two cell overlap. It can be seen in Figure 3 that, even though there is a significant difference between the $V_{o c}$ 's for the cells with and without the $R=40$ interface region at 1 sun illumination, at intensities less than about $10^{-4}$ suns the $V_{o c}$ 's are identical. This indicates that in this regime the $\mathrm{V}_{\mathrm{oc}}$ in both cells is determined by the properties of the same protocrystalline bulk layer, whereas, at the higher intensities the contributions of the different $p / i$ interface regions can be identified. It is interesting to note here that both the $J_{s c}-V_{o c}$ and the $J_{D}-V$ (Figure 1) characteristics overlap up to $\sim 0.4 \mathrm{~V}$.

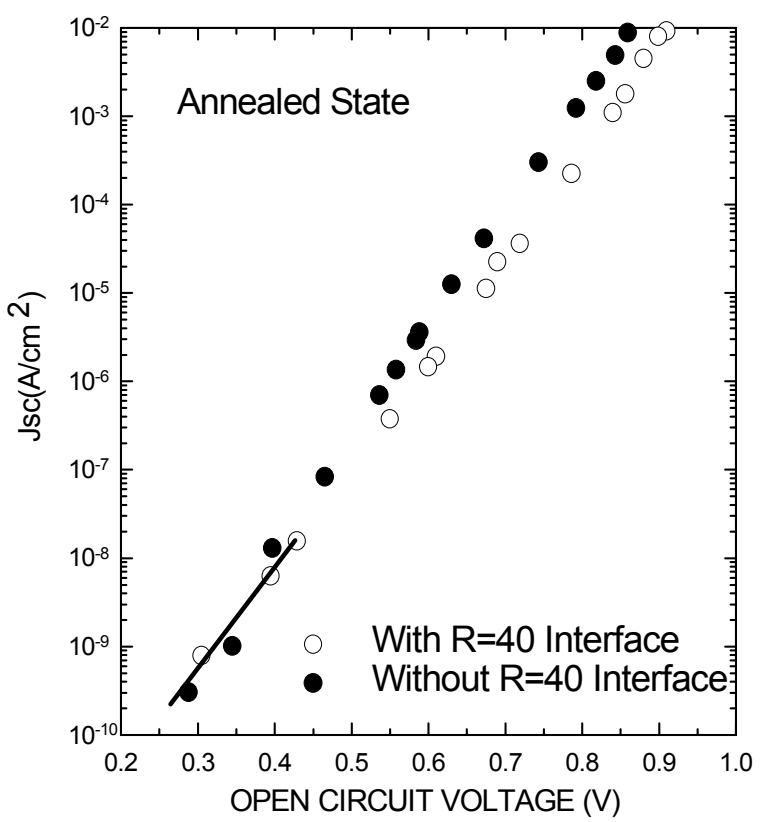

Fig. 3. The $\mathrm{V}_{\mathrm{oc}}-\mathrm{J}_{\mathrm{sc}}$ (light intensity) characteristics of an $R=10$ cell and an $R=10$ cell with an $R=40$ p/i interface region in the annealed state.

Such a contribution of the bulk is further confirmed by the results obtained after the two cells have reached a degraded steady state (DSS) under one sun illumination. It is expected that as the quality of the bulk declines the region over which the contribution of the $p / i$ interface can bee seen should decrease, and in the case of poor quality material could disappear completely. The light induced degradation to DSS reduces the quality of the bulk by introducing about $10^{17} \mathrm{~cm}^{-3}$ defects, where these defects increase the generation- recombination currents about by a about a factor of ten.

The annealed state and DSS for the baseline $R=10$ cell are shown in Figure 4. Although there is an absence of any major change in the $V_{o c}$ with 1 sun illumination, at lower illumination intensities there is a marked difference between the two characteristics. Due to the light induced degradation of the i-layer the region over which the bulk dominates is extended to intensities of $10^{-3}$ suns for this baseline cell.

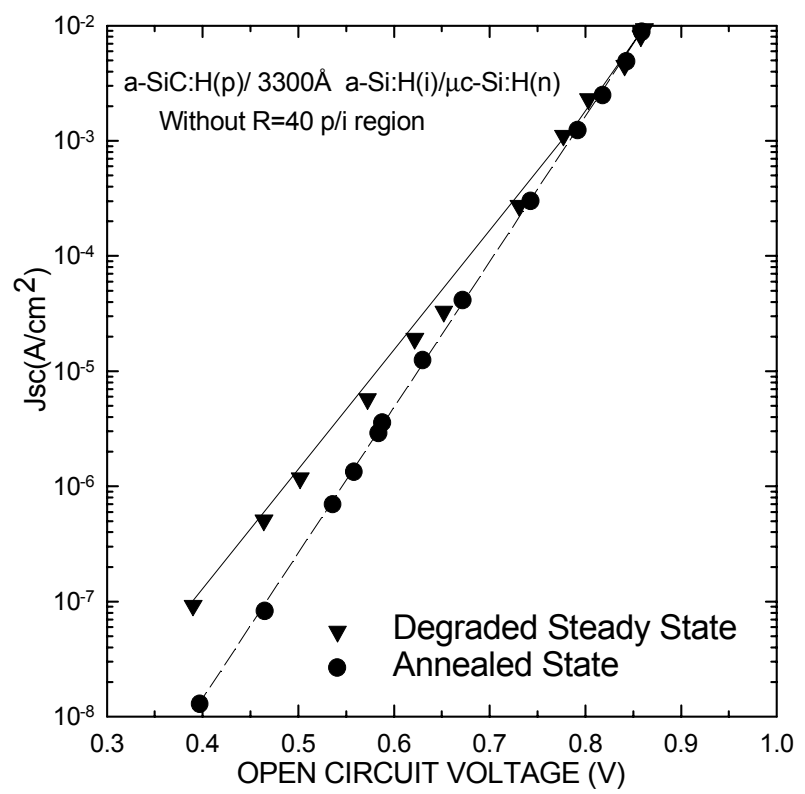

Fig. 4. The $\mathrm{V}_{\mathrm{oc}}-\mathrm{J}_{\mathrm{sc}}$ (light intensity) characteristics of an $\mathrm{R}=10$ cell in the annealed and degraded steady states

The same phenomenon is seen in Figure 5 for the cell with an $\mathrm{R}=40 \mathrm{p} / \mathrm{i}$ interface region. In this case, however, there is a small drop in the 1 sun $V_{o c}$ at 1 sun illumination. The light induced degradation in the i layer extends the bulk domination to 1 sun for this optimized cell. It should be noted that at higher intensities ( $\sim 50$ suns) the annealed and DSS characteristics for this cell also merge together, similar to the baseline case, and there is no decrease in $\mathrm{V}_{\mathrm{oc}}$.

\section{DISCUSSION}

The results presented and discussed above show how the bulk and p/i interface contributions to dark J-V and $\mathrm{J}_{\mathrm{sc}}-\mathrm{V}_{\mathrm{oc}}$ characteristics can be identified and quantified. The extended exponential dependence of the currents on voltage seen in both the dark $\mathrm{J}-\mathrm{V}$ and $\mathrm{J}_{\mathrm{sc}}-\mathrm{V}_{\mathrm{oc}}$ characteristics can be expressed by a classical diode equation as:

$$
\mathrm{J}=\mathrm{J}_{\mathrm{O}}[\exp (q \mathrm{q} / \mathrm{mkT})-1]
$$

where $J_{0}$ is an effective reverse saturation current density and $\mathrm{m}$ is an operational diode quality factor over that region. Since the values of $m$ are determined by the voltage dependence of recombination of injected carriers such operational diode quality factors have several components. This include the effect of i layer thickness, and the density and distributions of recombination centers and in addition to this bulk component there is one due to recombination at the interface. A seen in Figure 3, in the 


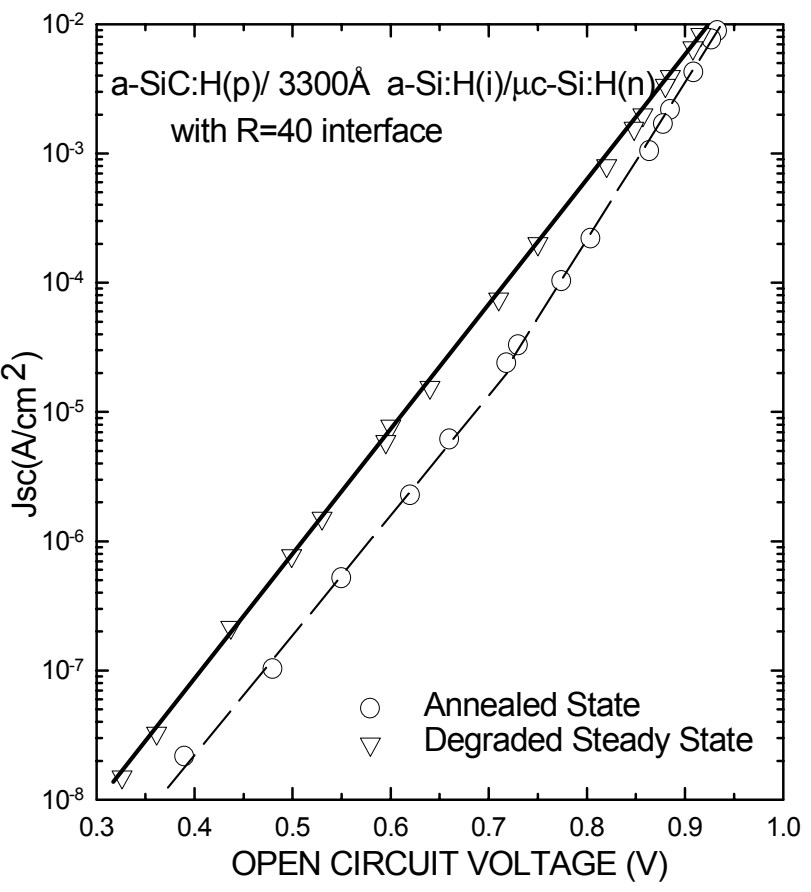

Fig. 5. The $V_{\text {oc }}-J_{s c}$ (light intensity) characteristics of the cell with an $R=40 \mathrm{p} / \mathrm{i}$ interface region in the annealed and 1 sun degraded steady state.

annealed state at low intensities both the baseline cell and the one with the optimized $\mathrm{p} / \mathrm{i}$ interface cell have $\mathrm{m}=$ 1.6. In the case of the baseline cell, however, a value of $\mathrm{m}=1.3$ occurs at $\mathrm{V}_{\text {oc }} \mathrm{S}$ greater than $0.4 \mathrm{~V}$, where in the case of the $R=40 \mathrm{p} / \mathrm{i}$ interface cell this does not occur until $\sim 0.7 \mathrm{~V}$. The decrease in $\mathrm{m}$ value can be attributed to recombination that is dominated by the interfaces for these cells. It can be seen in Figure 5 that for the $R=40 \mathrm{p} / \mathrm{i}$ interface cell in the degraded steady state, a single value of $\mathrm{m}$ now extends to 1 sun illumination indicating that there is a single contribution to the recombination processes. This implies that the recombination due to the higher density of defects, introduced by light, now dominates over that at the $\mathrm{p} / \mathrm{i}$ interface all the way to $V_{o c}$ for 1 sun illumination. Separating and quantifying such $m$ values in jsc-Voc characteristics offers important information about the nature of the bulk and p/i interfaces. However, it should be noted that neither the p/i interface nor the bulk values of $\mathrm{m}$ are unique for all high quality a$\mathrm{Si}: \mathrm{H}$.

Hence, it is found that in high performance solar cells the recombination and $V_{o c}$ need not be limited by the $p / i$ interface. The results presented here also clearly indicate that estimates for the maximum 1 sun $V_{o c}$ and the built in potentials cannot be estimated given results on cells whose $\mathrm{J}_{\mathrm{sc}}-\mathrm{V}_{\mathrm{oc}}$ characteristics are dominated by generation-recombination at the $\mathrm{p} / \mathrm{i}$ interface [2]. Detailed results of the role of carrier recombination on these characteristics as well as their effect on limiting the maximum $V_{\text {oc }}$ that can be obtained with given bulk layers will be discussed elsewhere.
The separation of bulk and p/i interface contributions to the characteristics discussed here offer meaningful inputs into self consistent analysis of solar cell characteristics which does not rely on arbitrary and ad hoc assumptions about the nature of the p/i interface. In addition, the results illustrate that $V_{o c}$ 's at 1 sun can be stable when they are limited by the $p / i$ interface regions and not the bulk $\mathrm{i}$ layers and that any valid analysis must be based on results over a wide range of intensities. It is also imperative in any analysis to ensure that the modeling be carried out first on cells whose characteristics are indeed dominated by the bulk and only then can the contributions of various $p / i$ interfaces subsequently be realistically analyzed. Such analysis has been undertaken on the characteristics, which have been shown to be bulk-dominated and self consistency is being established based on "operational" gap state parameters obtained from Schottky barrier [10] and thin film studies [11].

\section{ACKNOWLEDGEMENTS}

We would like to acknowledge the support by the National Renewable Energy Laboratory (NREL) under subcontracts HXAF-8-17619-22 and the New Energy Development Organization (NEDO) International Joint Research Grant.

\section{REFERNCES}

[1] H. Sakai, T. Yoshida, S. Fujkake, T. Hama, Y. Ichikawa, J. Appl. Phys. 67, 1990, p.2494.

[2] Hegedus, S.S., Salzman, N., Fagen, E., J. Appl. Phys. 63, 1988,p. 5126.

[3] Koh, Joohyun, Ferlauto, A.S., Rovira, P.I., Koval, R.J., Wronski, C.R., Collins, R.W., J. Non-Cryst. Sol. 266 1999, pp. 43-47.

[4] Randy J. Koval, Joohyun Koh, Z. Lu, L. Jiao, R. W. Collins, and C.R Wronski, Appl. Phys. Lett. 75, 1999, p. 1553.

[5] Koval R.J., Koh J., Lu Z., Lee Y., Jiao L., Collins R.W. and Wronski C.R., Mat. Res.Soc. Symp. Proc. 557, 1999, pp. 263-268.

[6] Lee, Y., Jiao L., Koh, J., Fujiwara, H., Lu, Z., Collins, R.W., and Wronski, C.R, Mat. Res. Soc. 467, 1997, pp. 747.

[7] Lee, Y.; Ferlauto, A.S.; Wronski, C.R., Conf. Record of $27^{\text {th }}$ IEEE PVSC, (IEEE, New York), 1997, p.683.

[8] Y. Lee, L. Jiao, H. Liu, Z. Lu, R.W. Collins, and C.R. Wronski, Conf. Record of the $25^{\text {th }}$ IEEE PVSC, (IEEE, New York), 1996, p.1165.

[9] Lee Y., Ferlauto A.S., Lu Z., Koh J., Fujiwara H., Collins R.W. and Wronski C.R. Proc. $2^{\text {nd }}$ World Conf. on Photovoltaic SolarEnergy Conversion, 1998, pp. 940-943. [10] Lu Z., Jiao H., Koval R., Collins R.W. and Wronski C.R., Mat. Res. Soc. Symp. Proc. 557, 1999, pp. 785790.

[11] Jiao, L., Semoushikiana, S., Lee, Y., and Wronski, C.R., Mat. Res. Soc. Proc., 467, 1997, p. 97. 